\title{
A copa do Juazeiro é verde, as raizes são alagoanas
}

\author{
Joazeiro's treetopis green, the roots are from Alagoas
}

Francisco Airton Bastos Silva Filho*

https://doi.org/10.29327/256659.12.2-11

Resumo:

O presente artigo é parte da integra de etnografia realizada entre os anos de $2018-2020$, no município de Juazeiro do Norte, que teve como objeto: etnografar o ritual de peregrinação e visita ao túmulo do Pe. Cícero Romão Batista por um grupo de oito romeiros do estado de Alagoas. Especificamente, o corrente texto, trata da identidade do romeiro, onde tem no de Alagoas, uma das maiores representatividades: histórica, cultural, humana e social. Destaca-se o protagonismo do romeiro, a espontaneidade e autenticidade da cultura romeira no Juazeiro do Norte e a corporalidade do romeiro alagoano em sua performance/ritual como sendo sua marca e característica mais marcantes. O artigo ainda desvela elementos históricos/culturais do catolicismo popular resistentee que se mantém até hoje na cultura do romeiro de Alagoas.

Palavras-chave: Romeiros. Alagoas. Protagonismo. Ritual.

Abstract:

This article is part of ethnographycarried out between 2018-2020, in Juazeiro do Norte city, aiming to do ethnographyon the pilgrimage ritual and visit to the tomb of Father CíceroRomão Batista by a group of eight pilgrims from the state of Alagoas. The current text specifically deals with the identity of the pilgrims, who has in Alagoas one of their greatest historical, cultural, human and social representations. The pilgrims' protagonism stands out, as well asthe spontaneity and authenticity of the pilgrims' culture in Juazeiro do Norte, not to mentionthepilgrims' corporality from Alagoas in his performance/ritual as being his most striking mark and feature. The article also reveals historical/cultural elements of popular Catholicism that are resistant, keeping themselves even nowadays in the pilgrims'culture of Alagoas.

Keywords: Pilgrims; Alagoas; Protagonism; Ritual.

\footnotetext{
"Membro do Conselho Editorial da Editora Olyver. Membro e sócio correspondente da Academia Palmeirense de Letras - Palmeira dos Índios - Alagoas. Membro efetivo do Grupo de Estudo e Pesquisa em Religiosidade Popular Sociedade e Cultura (GPRESC). Licenciatura em História pela Faculdade Campos Elísios - São Paulo, SP. Mestrado em Antropologia Social pelo Instituto de Ciências Sociais da Universidade Federal de Alagoas (2018 - 2020). Membro efetivo do Coletivo de Estudos em Religião e Cura (CuRare). Membro pesquisador do Laboratório de Antropologia Visual de Alagoas - AVAL. E-mail: franciscobastos.36@gmail.com.
} 


\section{O Contexto das Romarias em Juazeiro do Norte}

As romarias no Juazeiro do Norte surgem como movimento social de uma religiosidadepopularmuitopungentefrenteaocatolicismoromanizado,natransiçãodo século XIX para o XX. (GUIMARÃES, 2011), ao citar Jacques (MÂ̂TRE, 1968), reconstrói com seu pensamento histórico esse expediente da religiosidadepopular.

Em sua constatação, o conceito de religião clerical religiosidade popular, tem seu sentido nas sociedades em que autoridades religiosas garantem forte regulamentação da ortodoxiae da ortopraxia.

Essa relação do catolicismo popular alimentada por uma religiosidade também popular e catolicismo romanizado sempre existiu, sobretudo, após uma sexta-feira, de $1^{\circ}$ de março de 1889 em que a hóstia sangra na boca de Maria de Araújo publicamente depois de inúmeras manifestações, segundo (NETO, 2009).Quatromesesdepois, em 7 dejulhodo mesmo ano, no domingo que marcava o ápice da festa cristã do "Precioso Sangue", Juazeiro do Norte recebe os primeiros 3.000 romeiros oriundos do Crato, cerca de dez vezes a população local.

Tem-se, então, o sacerdote acolhedor, conselheiro, o protagonismo e misticismo da beata que reacende o fervor dos movimentos religiosos e os romeiros sacralizando a pertença, formando, assim, as romarias de Juazeiro do Norte. Ainda sobre o catolicismo popular, Guimarães (2011, p. 05) escreve considerando J. Comblin (1968): "O Catolicismo puro não existe. Trata-se de uma visão do espírito e não de uma realidade concreta que se poderia observar".

Entre não "existir" e não poder generalizar, dentro da micro-história da antropologia social, fica mais claro particularizar dentro de uma estrutura aparentemente "homogênea". Em uma perspectiva simbólica, a relação humana e mística/divina com o Pe. Cícero e social dos romeirose o Juazeiro do Norte,é reflexo de uma construção em se tratando do catolicismo popular de Juazeiro, que é feita a partir da imaterialidade e da materialidade,do saber e do fazer doromeiro.

Em tempos contemporâneos, inevitavelmente e de forma dinâmica, sentem-se os efeitos do que se chama de pós-modernidade (HALL, 2006), em que se dá uma maior atenção à micro-história, às diversidades e à subjetividade.

Oliveira (2004, p. 196) filósofo da Universidade FederaldoCeará, escreveu em que é muito complexoo assim chamado "ressurgimento do Sagrado",uma vez 
que o "modelo" de fé foi sem premoldadona perspectiva pré-moderna. Essa perspectiva pode ser analisada pela óptica dos três agentes de StuartHall: o iluminista, o sociológico e o pós-moderno. Penso que essa afirmaçãodeuma "complexidade do ressurgimento do Sagrado"só se sustenta se não se diversifica; se considera-se apenas o sujeito centrado, unificado, eurocêntrico, etnocêntricocomo descreve Hall (2006, p. 10). Sobretudo após 1960 comuma "abertura" da Igreja Católica Apostólica Romana, contudo, o romeiro bem antes, afirma-se com seu protagonismo.

\section{O Romeiro como Ator Cultural - onde está ele, aí está o Padrinho}

Aqui, o sujeito é o romeiro, cidadão do mundo, não isolado, interconectado e atuante, alimentador das romarias e devoto do Pe. Cícero. Revela-me que é protagonista, atuante, dinâmico e deslocado a partir de uma fragmentação do que se pensava até então do conceito de estrutura a partir de mudanças nas paisagens culturais de classe, gênero, sexualidade, etnia, raçaeracionalidade. E por que não acrescentar aqui, nas paisagens religiosas. Hall faz refletir que o romeiro é um su-jeito histórico e cultural acima de qualquer definição ou deslocado por forças fora de si mesmo (HALL, 2006, p. 17).

Interessante notar a observância dessa constância sendo descentrada por "forças fora de si mesma" e como se percebe esse fenômeno é mais histórico/antropológico que sociológico. Posso atribuir essa força exterior ao fenômeno da comunialidade percebida nas romarias, em que o romeiro se alimenta dos elementos simbólicos/místicos/religiosos e, portanto, culturais que, por meio de sua corporalidade, retroalimentam essa força.

Quando faloque este estudo é mais histórico/antropológico que sociológico, estou considerando que, bem mesmo antes de existir a romaria em sua coletividade/comunialidade, há um sentido de ir individual, uma intencionalidade e uma motivação que fazem os agentes das romarias serem os detentores da romaria. O exterior é resultado do que interiormente é projetado na forma "dos passos longos...", "dos benditos", “da visita ao túmulo" entre outros aspectos observados.

Hall (2006, p.11) ainda considera que a "noção de sujeito sociológico refletia a crescente complexidade do mundo moderno e a consciência de que este núcleo interior do sujeito não era autônomo e autossuficiente, mas era formado na relação com "outras pessoas importantes para ele". 


\section{Liminaridade e Communitas}

Para o romeiro, "outras pessoas" são o Pe. Cícero, a beata MariadeAraújo,o beato Zé Lourenço, a beata Bichinha, Roque Pinto e outros que, assim como eles, construíram e constroem a mística do que é Juazeiro doNorte.

Menciono o que está em "Papel passado..." de (LOPES, 2011) "onde o romeiro está, está o santo, e vice-versa". Dentro dessa hagiografia, considero o que escreve KUNZ (2011, p. 11) quando afirma que o padrinho sagrado e o padrinho profano são o mesmo; ele também foiperseguido e oprimido, assim como o romeiro que pede e, ao mesmo tempo dá, se oferece. Claro que nesse contexto, existem "outras pessoas, ou forças", mas o que se trata aqui está além de qualquer força ou hierarquização romanizada, pois está no campo da "simbologia interacional".

Historicamente está registrado que os movimentos religiosos denominados romarias dos romeiros do Pe. Cícero e da "terra da mãe de Deus", ressurgiram hámais de um século, opondo-se às tentativas de extinção do catolicismo popular e à normatização da romanização eurocêntrica. Esse catolicismo inserido na religiosidade popula revidencia o que escreve(HALL, 2006),"sujeitos totalmente descentrados e avessos à ideia de uma unificação normatizada de centralidade impositiva”. Se escrevo de protagonismo antes de depois do século XIX, a ideia de modelo construído, moldado por forças superiores, o que se observa em Juazeiro, é que o contraponto dessas forças, "catolicismo popular" e "catolicismo romanizado" sempre existiu.

Talvez, aqui se tenha uma ideia mais clarificada do conceito de "comunialidade", em que a estrutura religiosa do Juazeiro é formada pelo pluralismo de tradições culturais religiosas diversificadas, mas todas no âmbito do catolicismo, como os "Ave de Jesus"“os devotos de Pedro Batista e Madrinha Dodô", "os romeiros pedintes", além de muito pontual mente se observar também integrantes de religiões de "matrizes africanas e indígenas" pormeiodeumaespontaneidademuitoprópriasdosromeirosqueencontram em juazeiro a liminaridade e sua "Communitas" observada a partir de Tuner (1974) dentro da dimensãoalterizada. 
Complementa Oliveira (2004, p. 197) que "houve uma perda de força da institucionalização da religião" como algo de fora para dentro, e que se observa um movimento inverso, de interiorização de um fenômeno plural e multiforme, como são as romarias em Juazeiro do Norte. Não cabe mais um entendimento teórico,vendo as dinâmicas das romarias atuais, de uma ideia de romaria com "limitações" culturais, religiosas, de formatações fechadas ouisoladas. Hoje,tanto o catolicismo romanizado quanto o catolicismo popular convivem nos mesmos espaços dessa dimensão comum que possibilita a convivência "alter", mesmo que em alguns aspectos, ritualísticos e culturais haja diferenças de olhar e corporalidade entre o espaço construído institucional e a espacialidade do romeiro conceituada por Dumoulin (2018).

Contudo lembro que essas relações durante anos estiveram na dimensão mais "alios" onde era clara a existência de muros muito altos entre esses dois catolicismos, queaideiadeuma“redesocial"nãoerapossivel.Hoje se observam muito mais as pontes de alteridade, do que os muros hegemônicos, normativos e institucionais. A análise do conceito de redes sociais ajuda nesseexpediente.

\section{Redes, Conexões e Interconexões Culturais nas Romarias}

ApartirdasleiturasfeitasdostextosdeBarnes (1987)eHennerz (1997, 2015), Auge (2010), Agier (2015), compreende-se o conceito de rede social. Baseado em meu objeto de estudo, que é etnografar os movimentos religiosos, a peregrinação e a visita ao túmulo de Pe. Cicero, a partir de intenções e motivações que levam esses romeiros de Alagoas a Juazeiro doNorte.

O entendimento do estudo sobre redes sociais é algo que Hennerz (2015, p. 168) vai dizer: "aideia de redes na Antropologia significa abstrair de algum sistema mais amplo, para objetivos analíticos, conjuntos de relacionamentos mais ou menos elaborados". Esse expediente pela complexidade de um estudo dessa natureza, não é meu foco. Trago uma reflexão sobre os autores acima e a ideia pós-moderna de rede socialpara melhor clarificar o entendimento das conexões e interconexões e extra conexõesdas relações em Juazeiro dasromarias.

A ideia de rede social em Juazeiro do Norte baseada na concepçãode Hennerz (2015) pode ser analisada a partir da ideia tecnológica de rede,que está bem expressa nos textos, a rede social de Juazeiro do Norte e seus grupos aqui citados e objetos dapesquisa. 
De forma objetiva, sabemos que a análise da rede social das romarias em Juazeiro do Norte encontra fundamento em Hannerz (2015, p.168), com quem divido a mesma preocupação:

tornou-se necessário ter uma mente mais aberta com relação à delimitação das unidades de estudo, já que, com frequência, não podíamos depender dos limites sociais "naturais". De um lado, até a comunidade local podia ser uma unidade complexa e muito grande para ser analisada, e não necessariamente relevante de um modo geral para otipodeanálisequetínhamosemmente. Por outro lado, não podiamos deixar de considerar as conexões que estavam fora dela, com a região, com a nação, com o resto do mundo.

Sendo as romarias de Juazeiro uma rede social total, mas não homogênea, absorve automaticamente as outras e suas interconexões; duas dessas redes mais dentro da análise, formadas por romeiros e nativos (artesãos,comerciantes,etc.), um pouco mais distante, mas notada nessa rede social, oturista por exemplo,em que socialmente falando, essa totalidade possui um fluxo religioso, cultural, social, econômico, turístico muito intenso e produtivo.

Essaredeto-

tal(Romarias/Juazeiro)éalimentadaprincipalmentepelosromeirose suas redes externas, cidades do Nordeste e que também recebem, nos últimos tempos, fluxos de outras regiões. Segundo D. Gilberto Pestana de Oliveira, Juazeiro, em 2018, recebeu uma leva significativa de romeiros do Rio de Janeiro, São Paulo e Paraná que alimentam as romarias dentro do município cearense e que são grupos de pessoas que enxergam e possuem conexões com o mundo lá fora, mas possuem seus conjuntos de relacionamentosinternos.

Essa relação em redes como interligação, inteiração e fluxo social, demonstrasua capacidade de interligar com maior afinidade seus membros e niveis mais abertos de interconexão, mas nunca são fechados, entre individuos que partilham experiências nos mesmos espaços e participam dos mesmosrituais.

Essas redes que são internas e externas, ao mesmo tempo, pois são dinâmicas e em Juazeiro se aglutina mês e espalham pelo movimento cíclico dasromarias,podemser lidas no grupo dos oito que protagonizam estapesquisa.

Maria Regina, Carminha, Zé Izídio, Maria Rosângela, Nilzete, todos deCoqueiro Seco, D. Luzinete de Joaquim Gomes, D. Zeze e Dalva de Maceió, a Fátima (Fau) de Paripueira, todos com vidas distintas, trabalhos, relações familiares dis- 
tintas, sociais distintas e comuns também entre seus familiares e relações sociais sem qualquer grau de parentesco, em Juazeiro em época de romarias, formam essa grande rede total composta por tantas outras redes e interconexões, fluxos, sempre no movimento de chegadas e partidas. Outros agentes protagonistas que aparecem ou espontaneamente me abordaram durante a etnografia, foram: o Senhor Antônio Ferreira de União dos Palmares; José Maurício, Secretário de Assistência Social de Maribondo; D. Adalgiza de Jesus de Mar Vermelho; Dona Creuza Luiza Lima da Silva de Maribondo, que alimentam essa rede social total alimentam com suas relações e acessamoutras.

Primeiro, a rede dos romeiros, observamos um grupo social que se nutre e retroalimenta a mística de Juazeiro do Norte com seu catolicismo popular, que, por sua vez, está em peregrinação rumo ao túmulo de Pe. Cícero que pode ser vista como a espinha dorsal que canaliza essas redes de pessoas e grupos que surgem de vários lugares. Sentido de uma liminaridade.

Dessas redes internas ou grupos, que têm por função agregar e concentrar todo o fluxo social e, por sua vez, o ritual de partida, peregrinação, visita ao túmulo e retorno às suas origens, podem também ser vistos como mantenedores necessários para a tradição dasromarias. É importante dizer que, nos últimos anos, várias mudanças ressignificam as romarias; contudo é salutar dizer que sua tradição existe e éconservada por várias ações. Uma dessas ações mais evidentes é a existência do Círculo Operário São José que tem à frente a irmã Annette, que executa um trabalho de recepção, acolhimento e preservação da cultura mais tradicional das romarias. Outro exemplo é o museu paroquial Monsenhor Murilo.

Os turistas, para diferenciar e exemplificar as redes distantes, mas conectadas às outras, romeiros, nativos com relações comerciais e de serviços, seriam outros grupos e também podem trafegar na rede total (Romaria) com menos densidade, pois sua visão seria mais exterior (estereotipada) em relação aos eventos de Juazeiro, que consistiria no olhar mais exótico e, por que não dizer, ocidental.

Os nativos, poderiam ser entendidos como membros locais, eles subsistem em Juazeiroe, nessa rede total, interagem com as duas redes internas mais diretamente.Nesse caso,esses indivíduos locais se conectam às redes internas da totalidade da qual fazem parte, por meio de produtos e serviços que oferecem, e nas relações sociais de afinidades entre esses grupos. 
Em relação aos grupos de romeiros, é preciso acrescentar para esse entendimento que, mesmo estando localizados em uma camada intermediária e não local, suas relações com a rede total ou como universo romeiro em Juazeiro do Norte é bem mais intensa do que as relações do turista com essa mesma rede total ou Juazeiro.

Seus membros quase sempre mantêm uma relação social perene,em queseusatores são mais assíduos na conexão comessa totalidade, e cujas renovações, partemde uma ancestralidade e tradição que,em estudos, não se observa na rede internadosturistas.

Por outro lado, a rede interna dos turistas, embora mais transitória na maioria dos casos,com raríssimas exceções, movimenta a rede em sua camada total em sua economia de produtos e serviços turísticos que, por este grupo social, são bem mais apreciados em sua totalidade.

Por fim, fica mais claro responder ao que Hennerz (2015) escreve em relação a abstrair o sistema mais amplo,para objetivos mais analíticos e mais ou menos elaborados.

Estar em Juazeiro do Norte, na romaria com os protagonistas alagoanos, é estar conectado a essa grande rede social de várias interconexões, com atmosfera cosmopolita descentralizada de uma antropologia transcendental (AGIER, 2015).

Esse relato é uma forma introdutória para descrever o entendimento de quem é o romeiro alagoano, seu protagonismo e o porquê desse movimento humano social e suas relações na rede total Juazeiro do Norte e nas inúmeras redes que atendem ao chamado das romarias, aqui mais especificamente o de peregrinação e visitação ao túmulo de Pe. Cícero.

Ler o testemunho de que Pe. Cícero era um "santo na terra" é trazer à tona o que se revela na pesquisa "o santo existe e permanece vivo, porque existe o romeiro"; querer ir ao encontro até hoje em peregrinação e ritual é performance de uma imaterialidade; estar em Juazeiro do Norte, peregrinar e visitar o túmulo é a ação da imaterialidade.

Como explicar essa atração e caminhada alagoana ao túmulo de padre Cícero Romão Batista? Como entender o porquê de tantos alagoanos fixaram morada em Juazeiro e que contribuíram significativamente para seu desenvolvimento como foi o caso do senhor Aureliano de Atalaia - AL, comerciante e pai de 36 filhos, Cap. Fernandes desenvolvedor da região também oriundo de Alagoas, se- 
nhor Roque Pinto de Anadia, Alagoas, primeiro administrador da capela do Socorro.

Embora não seja alagoana, para compor esse panteão de romeiros seminais, fazendo alusão a Geertz (2008), destaco ainda a Maria Magdalena do Espírito Santo de Araújo, abeatado milagre,protagonista de uma das mais complexas e importantes ações no contexto das romarias.

\section{Quem é o Romeiro (a)??? Sua vida é andar...}

Mas, enfim, quem são esses protagonistas alagoanos que formam o grupo de romeiros que dão vida a esta etnografia?

Maria Regina, a Maria da Xoxa, nascida em 1960, moradora de Coqueiro Seco, Alagoas, é enfermeira, ministra da eucaristia, neta de romeiros, romeira há quase meio século e, na ocasião da romaria de 20 de julho de 2018, fazia oito meses que seu filho mais velho havia sido assassinado. Enlutada, ela traz em sua voz, enquanto caminha para iniciar a subida do horto, o seguinte: "tem muita gente que vê a cruz como sinal de sofrimento; a gente tem que ver a cruz como exemplo e agradecimento". Estando em Juazeiro, mais perto de "meu padrinho Cícero", Maria Regina diz que, "além da dor do luto que diminuiu bastante, todas as outras dores se vão e até volto a sorrir após oito meses".

Sua mãe era fretantee lembra que desde os 12 anos vêm a Juazeiro do Nor-te. Faz sempre três romarias: a de candeias em janeiro/fevereiro, a de morte do Pe. Cícero em julho e a de Mãe das Dores em setembro.

Peregrinando com seus passos longos de pedra e areia que se junta aos tantos outros, rumo ao santo sepulcro, equilibrando uma garrafa de água em suacabeça, me diz, "professor, enquanto tiver força, não deixo meu Juazeiro e nem meu padrinhoCícero".

Maria do Carmo dos Santos (Carminha) é aposentada, moradora de Coquei-ro Seco, Mestra de Folguedo, filha de fretantes, mãe de fretante (André Ezidio), eximia cozinheira, foi uma das primeiras a falar de suas histórias e memórias de tantas romarias. Conta que foi curada de uma grave enfermidade nas pernas por intercessãode Pe.Cícero e que recorre a ele paratudo. 
$\mathrm{Na}$ ocasião da peregrinação que fizemos juntos, durante a subida de quase $15 \mathrm{~km}$ ladeira acima, era visivel o inchaço em seus pés, mas no seu ritmo completou a peregrinação dizendo que subia com fé e alegria.

José Ezídio dos Santos, 69 anos esposo de Carminha, é aposentado reformado da polícia militar do Estado de Alagoas, morador de Coqueiro Seco, filho de romeiro, apreciador e versado na história do Brasil, a quem tive a grata satisfação de tê-lo como companheiro nas andanças por entre ruas e ladeiras de Juazeiro do Padre Cícero. Ele diz "ei professor... escute muito bem... padre Cícero para mim foi-se embora depressão, desemprego, ele é um santo, não é Deus, mas é santo".

Maria José dos Santos Silva (Nilzete) viúva, moradora de Coqueiro Seco, irmã da ex-prefeita da cidade, condição que é revelada pelos outros protagonistas, romeira de longas datas, embora tenha compartilhado comigo as duas poltronas do ônibus, é a mais reservada, que depois, na dimensão alterizada, me revelou um largo e sincero sorriso. Eu havia ultrapassado a dimensão no aceite dessa romeira que percebeu minha atitude ética em participar da romaria para ela e para mim, elaborando o método prático do campo.

Rosângela Maria de Lima Santos, professora, moradora de Coqueiro Seco, a com menos viagem a Juazeiro do Norte, tem em suas primeiras palavras quando chegávamos aohorto a seguinte memória: "foi aqui professor, em 2017 que me encontrei com o padre Cícero. "Sabe, professor, a fé do povo é a força do Juazeiro".

D.Luzinete,de78anos, é natural de Joaquim Gomes, Alagoas. Reside atualmente em Maceió, bisneta de romeiros e devota de Nossa Senhora do Monte Cabeça, é tirante de Benditos, isto é, é quem inicia, puxa os benditos que são acompanhados por outras pessoas e ao cantar o bendito de Santa Quitéria, olha para câmera como que olhando para meus olhos e pergunta: "tá vendo meu filho, que coisa linda? ". D. Zezé, que reside em Maceió, e D. Fatima (Fau) da Paripueira, bem mais reservadas, mas solícitas de nossa atenção, acompanham D. Luzinete nosbenditos.

Essa análise e apresentação dos primeiros romeiros e, me sugere o estudo da Antropologia do Corpo, como metodologia teórica aos resultados de prática de campo realizada entre os dias 14 e 20 de julho de 2018, em Juazeiro do Norte, 
por ocasião da romaria de morte de Pe. Cícero será mais bem aprofundada nesse capítulo.

A etnografia possibilitou, para mim, a fusão entre a prática de campo e a teorização desses resultados qualitativos na pesquisa. Com a antropologia do corpo foi possível a reflexão dos elementos observados a partir do conceito de sinergia, expressão, toques, gestos, olhares e comportamentos do grupo de oito protagonistas.

O romeiro alagoano é puro toque, expressão, olhar. Observar o grupo dos oito realizando a romaria do dia 20 , dentro da perspectiva do processo ritual e da antropologia do corpo, essa corporalidade do romeiro alagoano encontra-se e se coloca perante o mundo a partir do seu entendimento como agente formador de um processo a partir de seu corpo como agente e não como objeto e de sua corporalidade. Csordas (2008, p. 103) utiliza o pensamento maussiano para justificar a corporalidade em que o próprio Mauss sugere que "todos os humanos possuem uma noção de individualidade espiritual e corporal", esse paradigma se reafirma ao observar os protagonistas das romarias, no processoritual. O romeiro peregrino, sua vida éandar. O sentido do verbo "andar" sempre fez parte do contexto nordestino, está nas canções, nos versos, nos benditos, principalmente na prática das romarias.

Cordeiro (2010, p. 55) escreve:

A noção de peregrinação incorporada no discurso religioso supõe um percurso em direção ao divino e é compreendida tanto em um sentido material de um deslocamento geográfico quanto de um ponto de vista metafórico, correspondente a uma jornada interior.

Analisando o andar do romeiro peregrino considerando o recorte histórico apartir de 1889, pude observar que esse sentido do andar na prática, assume posturas diferentes em direção à cultura das romarias levando em conta "o sentido do pedir", "o sentido do receber e retribuir" e "o sentido da manutenção dessadevoção".

Nos estudos sociológicos, a peregrinação faz parte das práticas rituais características do sistema de crenças que constituemo aspecto religioso da vida. Sua apreensão está voltada para as implicações dessa prática no processo social. Entendendo a religião como construção humana sob o "guarda-chuva" da cultura, os fenômenos de deslocamentos religiosos contemporâneos envolvem 
várias perspectivas de interpretação a respeito das ações e sentidos evocados pelos agentes envolvidos. (CORDEIRO, 2010, p. 57).

Maria de Araújo, Zé Lourenço, os alagoanos contemporâneos ao Pe. Cícero Roque Pinto, Aureliano, Capitão Fernandes e tantos outros que peregrinaram até o Juazeiro depois de 1874 e 1889, buscaram por meio da peregrinação "o pedir" socorro o acolhimento, e dias melhores. Foram socorridos, acolhidos e encontraram dias melhores por meio de uma dinâmica e práxis igualitária que fez Juazeiro do Norte se desenvolver, do qual eles fizeram parte ativamente.

Até1934,anodamortedoPe.Cícero,ofluxoderomeirosvindosdeváriaspartes do Nordeste viam o Juazeiro do Norte como "meca"e o Pe. Cícero como o padrinho conselheiro, perseguido pela Igreja que ele tanto amou e preocupado com a causa dos mais pobres, oprimidos edesgraçados.

Esse caráter provedor do Juazeiro aos que chegavam, entre romeiros, beatos e toda sorte de pessoas por meio da pastoral do sacerdote, permanece alimentando o fluxo das romarias. Dumoulin (2017, p. 247) afirma "e ele fez opção pelos pobres. Consagrou sua vida aos pobres".

Sobre esse expediente, a opção pelos pobres, mesmo sendo nítido o desinteresse por parte do romeiro alagoano sobre qualquer elemento acerca da polêmica e controvertida "riqueza" de Pe. Cícero cabe aqui fazermos de forma muito sintética mas fundamentada, uma análise sobre a questão.

Para isso, vou utilizar a memória privilegiada da leitura do testamento do próprio Pe. Cícero por ocasião a visita ao Memórial Padre Cícero em Juazeiro do Norte em julho de 2018 e que foi transcrito para um livro escrito por Manoel Bergström Lourenço filho em 1926.

Não obstante aos desvios de caráter, condição nata dos homens, do desrespeito daqueles que posteriores ao Pe. Cícero usufruíram e não tiveram a hombridade de descontruirasmentiraseequívocosbibliográficos, deseutestamento, estãoexplicadosa“riqueza"eopoderdePe.Cícero. Aintençãodosacerdotefoisempre a melhor, o desrespeito de muitos foi sempre maior. Na biografia de Pe. Cícero existe uma figura intrigante chamada Floro Bartolomeu que segundo Amália Xavier era uma pessoa perigosa e que de seus atos arbitrários como por exemplo a concessão de patente de capitão a Lampião e o pacto dos coronéis tenham respingado acidamente na batina de Pe. Cícero lhemaculando. Cavalcante(2008, p. 277) transcreve uma resposta dada a ela por romeiros adeptos ao beato José 
Lourenço sobre o comportamento do sacerdote em doar bens à igreja,a reposta foi esta:"o santo se completa nas provações, que por sua vez desmascaram aqueles que impõe estes sacrificios. O Padre Cícero precisava mostrar ao povo quem eram realmente os bons homens da igreja, para que fosse visto que muitos sacerdotes são oanticristo". Aqui se pode dizer que muito claramente, Pe.Cícero explicita que sem o romeiro, Juazeiro acabaria, ou seja, não bastaria os "beneméritos" padressalesianos.

Emcontraparti-

da,paraumajustaanálisedestacooqueescreveuAnselmo(1968,p. 501), através de um testemunho de Vicente Pereira da Silva,citado pelo também escritor Abelardo F. Montenegro, em que Pe. Cícero teria dito "O que Deus não quer, o diabo não enjeita. A igreja não me quer, pois eu memetonapolítica”. Essa opinião jamais encontrou coro entre pesquisadores como professor Daniel Walker, Renato Cassimiro, Renato Dantas, Marcelo Camurça, José Genildo Reges, Maria do Carmo Pagan Forti, entre outros e nem tão menos em publicações sérias sobre o Juazeiro segundo esses mesmos pesquisadores. Será a opinião dos romeirosdiferente?

Fecho aqui essa questão tendo a consciência que essa sintética análise, nem ao menos abalou o campo denso dessa polêmica que se sustenta em dois pilares: O padre Cícero "santo" e provedor do social e o padre Cícero Coronel, concentrador de riquezas, sobre o qual paradoxalmente (WALKER, 2017, p. 21) escreve:

E assim, com altos e baixos, errando e acertando ao longo de quase um século de existência como religioso e político, Padre Cícero construiu e consolidou uma biografia de primeira linha, e seu nome, até hoje, é objeto de estudo, despertando ódio e amor. Ele teve a grandiosidade inerente aos grandes homens e as fraquezas comuns a todo mortal. Contudo, foi uma pessoa extraordinária, afigura mais estudada do clero brasileiro, o homem que colocou Juazeiro no mapa do Brasil e o mais carismático líder político e religioso do Brasil.

Retornando à escrita sobre os fluxos, após a morte de Pe. Cícero em 20 de julho de 1934, historicamente o fluxo de romarias aumentou sem precedentes, incialmente pelo choque e sentimento momentâneo de orfandade física, que logo foi ressignificada em devoção. Segundo Cordeiro (2010, p. 57), "além de sinônimo de peregrinação, o termo romaria é utilizado para designar uma reunião de devotos. 
Com essa reunião e devoção, um sentido de pertença que era construído no processo de mistificação de 1889 passa a ser observado. Dantas (2018) fala até de uma questão mítica, construção oral na qual o Pe. Cícero havia sido levado por anjos ao céu e pedido aos romeiros que continuassem seu legado na terra do Juazeiro do Norte com as peregrinações.

O movimento desse fluxo passa, então, a ser alimentado pela volta desse romeiro que devolve a dádiva recebida pelo legado de Pe.Cícero, pela escolha dos romeiros, pelo protagonismo contemporâneo a ele e pelo sentido de pertencimento do romeiro alagoano na atualidade.

Mauss (2003, p.188) ao trazer algumas questões recorrentes durante toda essa explanação: qual é a regra de direito e do interesse que faz que o presente recebido seja obrigatoriamente retribuído? Que força existe na coisa dada que faz o presente recebido, ser obrigatoriamente retribuído? Isso me leva a problematizar o que leva romeiros de Alagoas retribuírem em forma de peregrinação/romarias, sacrificios suportados com resignação e alegria, as graças alcançadas e mais ain-da, o que faz essas graças serem dadas? A metáfora ${ }^{1}$ que dá título a esse artigo, assume sua materialidade na corporalidade e espontaneidade romeira tão presente e pungente, nas subidas e descidas, ruas e becos de Juazeiro do Norte. Na copa do frondoso Juá, a esperança é cantada nos benditos, ganha ação nos passos tão longos de pedra e areia, no olhar é no toque do romeiro. Estando à sombra dessa cidade, se vê na acolhida, na partilha, no sagrado popular, algo de muito peculiar, familiar e, logo se percebe que durante todo o percurso, para onde se olhe e chegue, para e descanse, as raízes desse inegável fenômeno humano/histórico/social que é o Juazeiro do Norte são alagoanas, desde então, até agora e sempre. A dádiva não morre.

\section{Referências bibliográficas}

AGIER, M.Migrações, Descentramento e Cosmopolitismo: uma antropologia das fronteiras. Maceió: EDUFAL, UNESP, 2015. Cap. 4, p. 155-202.

AUGE, M. Por uma antropologia da mobilidade. Maceió: EDUFAL: UNESP, 2010. Prefácio, cap. 1 e 6, p. 7-26 e 95-104.

ALMEIDA, R. R. de; HOLANDA, C. R. Memorial Padre Cícero e outras histórias / Nova Olinda: Fundação Casa Grande Cariri, 2018.

BARRETO, F. M. de Sá. Padre Cícero. $2^{\circ}$ ed. São Paulo: Editora Loyola, 2002.

BARROS, I. Os Mitos do Sertão. Maceió, 2011 
BARROS, L. O.C. Juazeiro do Padre Cícero: a terra da mãe de Deus. $2^{\circ}$ ed.Fortaleza: Editora Imeph, 2008.

BENEDICT, R. Padrões de cultura.Trad. de Ricardo A. Rosenbusch. Petrópolis: Vozes, 2013.

BENI, M. C. Análise Estrutural do Turismo. $10^{\circ}$ ed. (atualizada). São Paulo:SENAC, 1997.

BLOCH, M. Apologia da História, ou, O oficio de historiador. Trad. de Andre Telles. Rio de Janeiro: Editora Jorge Zahar, 2001.

BRAGA, A. M. da C. Padre Cícero: Sociologia de um Padre,Antropologia de um Santo. Bauru: EDUSC, 2008.

BRAGA, A. M. da C. A Subida do Horto: Ritual e Topografia Religiosa. Debates do NER. Porto Alegre: UFRGS, ano 15, n. 25, jan.-junho de2014.p. 197-214.

BRANDÃO, S.; MARQUES, L. C. L.; CABRAL, N. D. A. e MORAES, A. (org.).História das religiões no Brasil: volume 5. Recife: Ed. Bagaço/Universitária da UFPE, 2010.

CANCLINI, N. G. O patrimônio cultural e a construção imaginária do nacional. Revista do Patrimônio Histórico e Artístico Nacional. Brasília: IPHAN, n. 23, 1994.

CAVA, R. D. Milagre em Joaseiro. $3^{\circ}$ ed. Trad. de Maria Yedda Linhares. São Paulo: Companhia das Letras, 2014.

CORDEIRO. M.P.J. Entre chegadas e partidas: Dinâmicas das Romarias em Juazeiro do Norte. Tese(Doutorado em Sociologia). Fortaleza: UFC, 2010.

CLIFFORD, J. Sobre a autoridade etnográfica.A experiência etnográfica. Rio de Janeiro: UFRJ, 2011.

DEMO, P. Metodologia científica em ciências sociais. $3^{\circ}$ ed. (rev. e ampl.). São Paulo: Editora Atlas, CLIFFORD, J. Sobre a autoridade etnográfica. A experiência etnográfica. 2.ed., 1995.

DUMoulin, A.; GUIMARÃES, A. T.; FORTI, M. do C. P. Anais do III SimpósioInternacional sobre Padre Cícero do Juazeiro: e... quem é ele?Juazeiro do Norte: Banco do Nordeste, 2004.

DUMoulin, A. Padre Cícero - Santo dos Pobres, Santo da Igreja. São Paulo: Paulinas, 2017.

ECKERT, C.; ROCHA, A.L.C. da. A preeminência da Imagem e do Imaginário nos Jogos da Memória Coletiva em Coleções Etnográficas. Rio de Janeiro: ABA publicações. Porto Alegre: UFRGS, 2015. p. 101-116.

FOUCAULT, M.Os corpos dóceis.Vigiar e punir. História da violência nas prisões. Petrópolis:Vozes, 1987.

GEERTZ, C. Uma Descrição Densa: Por uma Teoria Interpretativa da Cultura.A Interpretação da Cultura. Rio de Janeiro: Zahar Editoriais, 2008. 
GONÇALVES, J. R. S. O Patrimônio como Categoria de Pensamento. ABREU, Regina; CHAGAS, Mário (org.) Memória e Patrimônio - ensaios contemporâneos. Rio de Janeiro: Lamparina, 2009.

GONÇALVES, J. R. S. Ressonância, materialidade e subjetividade: as culturas como patrimônio. Horizontes Antropológicos. Porto Alegre: UFRGS, v. 11, n. 23, 2005. p. 15-36.

GONÇALVES, J, R. S. Edward Sapir: Forma Cultural e Experiência Indivíduo.Sociologia\&Antropologia. Rio de Janeiro: UFRJ, 02(04), 2012. p. 25-33

GUIMARAES, Therezinha Stella; DUMOULIN, Anne. O Padre Cícero: por ele mesmo. Petrópolis: Vozes, 1983.

GUIMARÃES, Therezinha Stella; DUMOULIN, Anne. Romeiros/as e romarias em Juazeiro do Norte protagonismo de uma liturgia popular uma visão antropológica. Revista de Cultura Teológica. São Paulo: PUC-SP, v. 17, n. 67, abril-junho de 2009.

GUIMARÃES, Therezinha Stella. Padre Cícero e a nação romeira - estudo psicológico da função de um "Santo" no Catolicismo Popular.Fortaleza: IMEPH, 2011.

HALL, S. A identidade em questão. A identidade cultural na pós-modernidade. Rio de Janeiro: DP\&A, 2006. P.07-22.

HALBWACHS, M. Memória Coletiva e Memoria Individua.A Memória Coletiva. São Paulo: Vértice, 1990.

HANNERZ, U. Fluxos, fronteiras, híbridos: palavras-chave da antropologia transnacional. Rio de Janeiro: Contracapa, 1997.

LARAIA, Roque de B. Cultura: um conceito antropológico. $14^{\circ}$ ed. Rio de Janeiro: Jorge Zahar Ed., 2001.

MADEIRA, M.das G. de L.; SAMPAIO, W. C (org.). Missionários e Beatos nos Sertões Nordestinos - ações socializadoras e formativas (séculos XVIII-XX).Maceió: EDUFAL, 2011.

MAUSS, M. Sociologia e Antropologia. São Paulo: COSAC NAIFY, 2003.

MAUÉS, Raymundo Heraldo. A Mãe e o Filho como peregrinos: dois Modelos de peregrinação católica no Brasil. Religião e Sociedade. Rio de Janeiro: ISER, 2013.

MEDEIROS, D. H. de. Padre Cícero: o milagreiro do sertão? Rio de Janeiro: Editora do Brasil, 1989.

NETO, L. Padre Cícero: poder, fé e guerra no sertão. São Paulo: Companhia das Letras, 2009.

NEGRÃO, L. N. Revisitando o Messianismo no Brasil e Profetizando seu Futuro.RBCS. São Paulo: ANPOCS, v. 16, n. 46, junho de 2001.

NOBRE.E. Dos S. Ilustres desconhecidas: as beatas de Ibiapina no jornal "A voz da religião no Cariri”. Anais do XXVI Simpósio Nacional de História - ANPUH, São Paulo, julho 2011. 
NOBRE. E. Dos S. O sagrado e a teatralização do mundo: espaços de Salvação e purgação nos relatos das Beatas do Padre Cícero (1868-1870). Revista de História. São Paulo: USP, n. 169, julho-dez. de 2013. p. 381-409.

OLIVEIRA, R.C. O Trabalho do Antropólogo: Olhar, Ouvir, Escrever. Revista de Antropologia. São Paulo: USP, v. 39, n.1, 1996. p. 13-37

OLIVEIRA, R. C. Tempo e Tradição.Sobre o Pensamento Antropológico. Rio de Janeiro: Tempo Brasileiro,2003.

OLIVEIRA, J.P. de. Pluralizando tradições etnográficas: sobre um certo mal-estar na Antropologia. Cadernos do LEME. Campina Grande, v. 1, n. 1, jan.-jun. de 2009. p. 2-27.

OLIVEIRA, A. M. de; HERBES, N. E. Espiritualidade, Fé e Cura: um olhar sobre a Religiosidade Popular. Id on Line Rev. Psic. V.10, N. 31. Supl 2, Set-Out/2016 ISSN 1981-1179.

PEREIRA DE QUEIROZ, M. I. Messianismo no Brasil e no Mundo. São Paulo: Dominus/Edusp, 2003.

PIMENTEL, J. S. Os Milagres do Joaseiro. Caicó (Rio Grande do Norte): Typographia Democrata de J-Renaud, 1892.

RABELO, M. C.. A possessão como prática: esboço de uma reflexão fenomenológica. Mana. Rio de Janeiro: UFRJ, 14(1),2008. p. 87-117.

RABELO, M. C. Estudar a religião a partir do corpo: algumas questões teóricometodológicas.Caderno CRH. Salvador: UFBA, 24(61), 2011.p. 15-28.

RABELO, M. C. Religião e a Transformação da Experiência: notas sobre o estudo das práticas terapêuticas nos espaços religiosos. Mha. Florianópolis: UFSC,n. 7, 2007, p.125-145.

RABELO, M. C.Enredos, feituras e modos de cuidado. Dimensões da vida e da convivência no candomblé. Salvador:EDUFBA, 2014.

RAMOS, F. R. L. O meio do mundo: território sagrado em Juazeiro do Padre Cícero. Fortaleza: Imprensa Universitária, 2014.

RAMOS, F. R. L. Papel Passado- cartas entre os devotos e o padre Cícero. Fortaleza: Instituto Frei Tito de Alencar, 2011.

SANTANA, E. H. de M. Padre Cícero do Juazeiro: Condenação e Exclusão Eclesial à Reabilitação Histórica. Editora. EDUFAL, 2009.

SILVEIRA, Emerson J. Sena da. Turismo religioso popular? Entre a ambiguidade Conceitual e as oportunidades de mercado. Revista de Antropología Experimental. España: Universidad de Jaén, n. 4, out. de 2004.

SILVEIRA, Emerson J. Sena da. Turismo Religioso no Brasil: uma perspectiva local e global. Turismo em Análise. São Paulo: USP,v. 18, n. 1, maio de2007. p. 33-51. 
STEIL, C.A.;MARIZ, C.L.; REESINK, M.L. Maria entre os vivos. Porto Alegre: Editora UFRGS, 2003.

SOARES DO BEM, A. A Centralidade dos Movimentos Sociais na Articulação Entre o Estado e a Sociedade Brasileira nos Séculos XIX e XX. Educação e Sociedade. Campinas, vol. 27, n. 97, set.-dez. de 2006. p. 1137-1157.

SOBREIRA, Pe. A. O Patriarca de Juazeiro. $3^{\circ}$ ed. Juazeiro do Norte: UFC, 2011.

SOUZA, S. (Coord.). História do Ceará (vários autores). Fortaleza: Universidade Federal do Ceará/Fundação Demócrito Rocha: Stylus Comunicações, 1989.

TURNER, V. O Processo Ritual. Estrutura e Anti-Estrutura. Petrópolis: Vozes, 1974.

TURNER, V. Dramas, Campos e Metáforas. Rio de Janeiro: EDUFF,2008.

TURNER, V. Floresta de Símbolos: aspectos do ritual Ndembu. Niterói: Editora da Universidade Federal Fluminense,2005.

WAGNER, R. A presunção da cultura.A invenção da cultura. São Paulo: Cosac \& Naify, 2012.

WALKER, D. Padre Cícero, Lampião e coronéis. Fortaleza: Expressão Gráfica e Editora, 2017.

\footnotetext{
1 A metáfora "A copa do Juazeiro é verde, as raízes são alagoanas" se dá pelo fato da forte presença de romeiros alagoanos em todos os ciclos de romarias, além da própria construção social do Juazeiro do Norte, com muitos personagens que oriundos de Alagoas, escreveram sua história, estão enterrados no Juazeiro e muitos de suas posteridades ainda vivem na terra da Mãe de Deus.
}

Recebido em 29/06/2021

Aceito para publicação em 30/08/2021 